\title{
LA ESTIMACIÓN DEL ARTISTA DIECIOCHESCO A TRAVÉS DE LA ESTÉTICA ROMÁNTICA EN LA PRENSA ILUSTRADA ESPAÑOLA*
}

\author{
Marina GACTO SÁNCHEZ \\ mgacto@ucam.edu \\ Universidad Católica San Antonio de Murcia
}

\section{Resumen}

En este artículo se aportan algunas reflexiones sobre el afán de revitalización del arte hispano que se registra en las revistas ilustradas españolas del segundo tercio del siglo diecinueve. La penetración peninsular de los ideales nacionalistas europeos impulsa entonces la necesidad de descubrir la identidad cultural española y su realidad. En las artes puede detectarse un idílico retorno en búsqueda de una identidad perdida. En este sentido, a través de las publicaciones periódicas, se produce una continuidad ideológica, temática y estética. La observación del nacionalismo popular literario permite detectar la exaltación artística del siglo XVIII, que estudiamos con especial referencia a la profesión del grabador, cuya estima adquiere en este período histórico una importancia capital dentro de la práctica plástica. En el presente estudio trazamos un análisis de las bases literarias del momento, abordando paralelamente la consideración social de estos artistas y la revalorización de su figura pública

Palabras clave: prensa ilustrada, artista, Academia, estatus, grabado.

\begin{abstract}
In this paper we reflect on the revitalization of the Hispanic art shown on the Spanish illustrated press around the second third of the nineteenth century. The penetration in Spain of the European nationalist ideals prompted a need to rediscover the cultural identity and reality of the country. An idyllic return in search of a lost identity can

\footnotetext{
* Este artículo se ha realizado adscrito al proyecto «Imagen y Apariencia: identidad, expresión e indumentario en el arte español. Siglos XVI y XIX» con la financiación de la Fundación Séneca 08723/PHCS/08.
} 
be observed in the art scenario. Through the journals studied, we can establish an ideological, thematic and aesthetic trend. As result of the nationalism present in the press, the artistic exaltation of the eighteenth century art can be analysed. We especially focus our attention on the engraver occupation, whose esteem acquires then a paramount importance within the plastic practice. We establish a final assessment on these issues taking as reference the bases of the artistic literature, as well as the social consideration and public figure appreciation of these artists.

Keywords: illustrated press, artist, Academy, status, engraver.

El ecléctico Romanticismo literario, base del nuevo movimiento de la prensa ilustrada del siglo XIX, tiene sus raíces en el costumbrismo popular y en el nacionalismo que desarrolla el amor al pueblo. Tales publicaciones hispanas constituyen un medio de comunicación y un primordial instrumento ideológico que tendrá su reflejo en el arte de su tiempo. La penetración de nuevos ideales en la península impulsa la necesidad de descubrir la identidad cultural española, sentando las bases de la prensa periódica que abordamos. En paralelo al prestigio de los literatos románticos vemos surgir a los más célebres ilustradores españoles, cuya estima adquiere en este período histórico una importancia capital dentro de la práctica artística. Este nacionalismo popular literario nos permite detectar la revalorización de la figura pública de estos artistas. A ello contribuyeron dos instituciones creadas por entonces en Madrid, el Ateneo y el Liceo. Dentro de estos círculos del Romanticismo madrileño, que promovieron la popularización de las Bellas Artes, encontramos a escultores de la talla de Adán y Agreda, arquitectos como Villanueva, grabadores como Carmona o pintores como Francisco de Goya, Bayeu o Alenza ${ }^{1}$.

El pintor Federico de Madrazo-Kuntz, y su cuñado el literato guipuzcoano Eugenio de Ochoa, tomaron la dirección de la conocida revista titulada El Artista tras haber vivido juntos en París ${ }^{2}$. El primero se especializó en la dirección de los aspectos artísticos de la misma, mientras que el segundo se encargó de la coordinación de aspectos relacionados con la literatura. Estos autores escogieron el modelo de la revista francesa L'Artiste, que había comenzado

1. Alenza realizó un retrato de Francisco de Goya en el Café de Levante, este dibujo se conserva en la Biblioteca Nacional de Madrid. Aparece el aragonés «chiquitito, cuadradote, balzaciano y con anteojos». Cruzada Villamil se refiere al mismo como una representación con mucha «naturalidad, verdad y sinceridad», fruto de la amistad y el trato entre ambos artistas (Cruzada Villaamil 1865, págs. 304-306)

2. Ochoa en su exilio francés entre 1824 y 1832 contactó con el Romanticismo galo, fruto de ese conocimiento de la literatura francesa contemporánea es su traducción en 1841 de la novela de Victor Hugo titulada Notre Dame de París. 
a editarse en el país vecino en 1831. Los prestigiosos talleres tipográficos de Sancha, en una de sus últimas etapas de trabajo, se encargaron de la elaboración de la revista (López Sanz 2000).

El primer número de El Artista apareció el 4 de enero de 1835, con el anuncio de que saldría semanalmente en entregas de doce páginas, con una o dos estampas litografiadas en cada una de ellas. A pesar de su corta vida se trata de una obra capital del Romanticismo español y de una publicación novedosa y sólida para la época que consideramos (Alonso Cortes 1943, pág. 147)3. Algunos expertos estiman que representa la publicación periódica más significativa dentro del período romántico español (Rodríguez Gutiérrez 2011, págs. 449-450). Esta cuestión es defendida, entre otros por Peers, refiriéndose al mismo como «la principal atalaya de los románticos» (1982, pág. 417) y por García Melero (1998, pág. 216). A este respecto, Alborg señala que «ocupa un lugar de primer orden en la historia del romanticismo español y es una fuente capital para su estudio; así lo han subrayado todos los investigadores de la época y queda puesto de relieve por las copiosas menciones de las que ha venido siendo objeto» (1980, pág. 170).

En esta revista colaboraron unos sesenta escritores, siendo la de Ochoa la colaboración más extensa, hasta el punto de suponer una cuarta parte de las publicaciones firmadas (Alborg 1980, págs. 169-185). El segundo en extensión fue Pedro de Madrazo, hermano de Federico, que escribió cuentos, poemas y artículos sobre las Bellas Artes. Por otra parte, Valentín Carderera completa la lista de colaboradores regularmente asiduos. La revista familiarizó a los lectores con la historia de la pintura, la escultura y la arquitectura españolas, en especial con aquellas manifestaciones referidas a la Edad Media. En la parte ilustrada de la revista destacamos que Federico de Madrazo firmó un total de cuarenta y una estampas sobre las noventa y siete que aparecieron publicadas en total. Para su edición contaban con la colaboración del Real Establecimiento Litográfico que desde 1824 regía Federico de Madrazo, estando dicho organismo patrocinado por el Rey. A este respecto, la colaboración de artistas de la talla de Federico Madrazo, Carlos Ruiz de Ribera y Elena Feuillet supuso novedades esenciales frente a las series de estampas que había realizado el Real Establecimiento con anterioridad: «[...] la primera, porque se trata de estampas originales, no reproducciones; la segunda, porque en ellas se introduce en

3. Alonso Cortés justifica su opinión del siguiente modo: «Los artículos de crítica literaria que en él se publicaron, y sobre todo los del benemérito Don Valentín Carderera, de tanta novedad como solidez; la galería de retratos, con sus correspondientes biografías, donde figuraron hombres como Lista y Quintana; la colaboración de los poetas más significados a la sazón, dieron al Artista una autoridad preeminente entre los románticos». 
el grabado español el carácter del estilo romántico, que tendrá en la litografía uno de sus principales medios de expansión» (Gallego 1979, pág. 349).

La calidad estética de las láminas litografiadas aparecidas en la revista ha sido unánimemente celebrada por la historiografía artística, Félix Boix dedica a este respecto un temprano análisis de carácter técnico instrumental sobre las láminas litográficas, justificando el elevado precio de la publicación en relación a su gran calidad (1931, págs. 60-63). Vega González (1997-1998, pág. 371) destaca la perfección de esta depurada técnica litográfica, presente en El Artista, que sustituyó al grabado calcográfico equiparando la producción española a la elaborada en otros países de Europa. García Melero alaba este espíritu creativo y la calidad de las láminas en detrimento de su espíritu erudito y crítico (1998, pág. 217) mientras Carrete Parrondo subraya la calidad e innovación de las mismas (1988, pág. 113).

En comparación, Las Cartas Españolas ${ }^{4}$ (1831-1832) y El Correo de las Damas (1834-1835) que precedieron a El Artista en la utilización de estampas cromolitografiadas, habían empleado el grabado con menor intensidad y como mero atractivo gráfico añadido al texto escrito. Sin embargo, las láminas de El Artista, bien sean retratos, paisajes o bocetos de monumentos, cumplen una función ilustradora que va mucho más allá, puesto que se trata de estampas que hacen referencia a un texto narrativo del que forman parte indisoluble.

Estas publicaciones no solo se esforzaron en publicitar a incipientes artistas, sino que mostraron su descontento con la situación cultural en la que España estaba inmersa. Para levantar el nivel cultural proponían una serie de planes encaminados hacia la conservación de la herencia nacional. Se solicitaba así la creación de museos y se denunciaba la demolición de grandes obras monumentales por parte de la política del gobierno. Todo ello enlaza con el conocido concepto herderiano de volkgeist o «espíritu del pueblo», posteriormente adoptado por el movimiento romántico — «genio del pueblo» en la versión española- entendido como la versión colectiva de la historia de los pueblos, en la que se incluyen todos y cada uno de los aspectos y manifestaciones de la misma, desde la política hasta las costumbres, la literatura o las artes. La historiografía española será deudora de la definición alemana en estas primeras tesis románticas españolas cargadas de nacionalismo, buscando

4. Cartas españolas, o sea revista histórica, científica, teatral, artística, critica, literaria. Publicadas con Real Permiso, y dedicadas a la Reina Nuestra Señora, por José María Carnerero, Madrid. Comenzó a publicarse en marzo de 1831 y finalizó en noviembre de 1832. En un principio se publicaron en cuadernos de veinticuatro páginas, que se repartían mensualmente. Desde enero de 1832 salía los jueves de cada semana. 
enlazar épocas pasadas con un espíritu propio de nuestra nación (Hernando 1995, págs. 129-130). Aunque estas publicaciones creyeron hallarlo en el Siglo de Oro literario, tampoco descartaban el horizonte medieval. En relación a las Bellas Artes, Henares Cuellar ha señalado que «el eje del discurso historicista lo va a constituir la arqueología medieval» (1982, pág. 36).

El espíritu de estas revistas intentaba a su vez rescatar el nombre de aquellas figuras excelentes de las Bellas Artes españolas que habían sido abandonadas en el olvido. El mismo Ochoa, como director de El Artista, expresó sus intenciones al destacar que la publicación estaba dirigida a «personas que sin desdeñar lo positivo, aprecian lo ideal y saben que el hombre no es un mecanismo mecánico, sino una creación sublime, una emanación de la divinidad [...]». Esta declaración de intenciones, está estrechamente vinculada a la concepción idealista del artista como alter deus que es capaz de crear y considera que es preciso difundir este criterio en sociedad, para que dejen de considerar la actividad artística un oficio puramente mecánico. Son muchos los artículos en los que se reivindica la aceptación social del artista y la dignidad de su trabajo (Herrando 1995, págs. 102-106). También se refería expresamente al cambio de mentalidad y apertura que se vivía en Europa de la siguiente manera:

Indudablemente nos parece que la sociedad se halla en una época de movimiento y de transición; que a las antiguas creencias, prontas ya a eclipsarse para siempre, van sucediendo nuevas creencias, menos sólidas acaso, menos duraderas que las pasadas; sabemos que las revoluciones van extendiendo lentamente por todos los imperios sus galerías subterráneas, ramificaciones de la gran revolución central, cuyo foco es la capital de Francia (de Ochoa 1835, págs. 1-2).

En la década siguiente a la desaparición de El Artista, surgieron una serie de publicaciones herederas de su espíritu, tipología y efímera duración. Será con la llegada del Semanario pintoresco español cuando se establezcan los pilares básicos de un periodismo ilustrado, una revista de carácter enciclopédico que estaba ilustrada con grabados a madera contrafibra de calidades dispares entre sí. Cabe destacar en su vinculación con El Artista, que también era editado en la célebre imprenta de Sancha. Su origen está directamente relacionado con la figura literaria de Mesonero Romanos, que ejerció de colaborador para diversas publicaciones periódicas de la primera mitad del siglo XIX. Sus circunstancias personales le habían posibilitado salidas al extranjero por lo que conocía la prensa extranjera, de la cual adoptará modelos en las páginas del Semanario Pintoresco Español ${ }^{5}$. Esta revista es una valiosa fuente iconográfica

5. Semanario Pintoresco Español, Madrid, 1836-1857. Semanal. Suscripción tres reales. Ocho páginas de 252 x $160 \mathrm{~mm}$. Dimensiones que disminuyeron y aumentaron

Anales, 25, 2013, pp. 149-168 
por su gran belleza tipográfica y tuvo una gran acogida tanto por su estética como por su público potencial, pues ya no iba dirigida exclusivamente a una minoritaria élite intelectual. Su objetivo era difundir un tipo de periodismo nuevo, pintoresco e ilustrado, según la acepción de la época, donde trataría de analizar la historia y las costumbres españolas. El propio fundador era consciente de las dificultades que entrañaba la publicación de este tipo de periódico «a causa de la falta absoluta de artistas conocedores del grabado tipográfico y hasta de papel y de máquinas propias para su impresión» (Mesonero Romanos 1881, pág. 181).

Desde 1840 Mesoneros, que precedió a Fernández de los Ríos como director de la revista, se dedicaría a la literatura costumbrista, siendo el primer escritor capaz de reunir a un gran número de colaboradores para dar luz a Los españoles pintados por sí mismos. En el Semanario Pintoresco Español será el crítico de arte, pintor y reputado coleccionista Valentín Carderera el encargado de la sección «España Pintoresca, Viajes y Bellas Artes». Realizó breves artículos ocasionales sobre la obra pictórica de Zurbarán y de Goya, aunque no siempre cumplió con el contenido de las citadas secciones, puesto que no encontramos artículo alguno que pueda incluirse en el apartado «Impresiones de viaje».

En la mayor parte de los números que configuran esta publicación se advierte una insistente preocupación por el grabado, aspecto que, como hemos mencionado, favoreció la venta de sus ejemplares. Ya en el prospecto de la misma se indica que los primeros números de la publicación irían acompañados de sus correspondientes ilustraciones al igual que los periódicos extranjeros, pues sus fundadores determinaron:

[...] enriquecerlos con los primores del arte tipográfico, acompañando las interesantes descripciones históricas, científicas y artísticas que los componen, sendas viñetas que reproducen con exactitud los personajes, sitios, monumentos y producciones naturales que describen; más no queriendo hacer traición a su pensamiento principal de la baratura, adoptaron para este objeto el grabado en madera, ramo del arte muy descuidado hasta entonces, y que, gracias a esta interesante aplicación, ha llegado hace pocos años a una altura y delicadeza que apenas pudo sospecharse en un principio (1836, pág. 4).

Esta insistencia en el grabado se hace patente desde un principio, pues el 1 de junio de 1837 El Semanario dedica un estudio detenido al grabado en madera, desde los orígenes de su invención a la época actual con biografías de artistas

ligeramente a lo largo de su existencia. Se publicaba los domingos. Empezó a editarse el 3 de abril de 1836 y cesó el 20 de diciembre de 1857. El número total de volúmenes publicados es de veintidós. La suscripción anual costaba treinta y seis reales y el total de lo publicado ochenta reales. 
y sus retratos, todo ello acompañado de ilustraciones de grandes dimensiones que sirven de apoyatura al texto publicado (1837, págs. 615-619).

\section{La estética romántica: objetivos de las publicaciones ilustradas}

Estas revistas nacen en un momento de fuertes cambios sociales, Europa se sumerge en una situación de crisis de valores y la educación comienza a ser considerada un baluarte para el progreso. Bajo estas circunstancias particulares comenzarán a aflorar los álbumes de retratos de celebridades que vemos en las publicaciones ilustradas, con reproducciones de personajes reputados que pretenden dar a conocer al lector la historia de su nación para que pueda comprender la marcha de los acontecimientos (Gómez Baceiredo 2010). Estas publicaciones, con un deseo democratizador de la cultura, apuntan los siguientes objetivos de modo común (Calvo Serraller 1981, págs. 19-20):

- La necesidad de reconocer las figuras privilegiadas en la historia de los pueblos, que llegaran a simbolizar por sí mismas la historia y civilización de una época.

- La importancia de registrar los hechos pasados y la relevancia de las figuras memorables como ejemplo a seguir por la sociedad, así como la necesidad de apreciar la historia de los pueblos en relación a las acciones de personajes relevantes ${ }^{6}$.

- La conveniencia de crear en España biografías modernas y de ampliar las de otros extranjeros, de los que tenemos solo ciertos detalles vitales puntuales. Todas las biografías se presentarán así con una buscada objetividad informativa, rechazando posibles partidismos.

Respecto a la incorporación de artistas españoles en lo referente a las biografías, queda justifica puesto que en la mayoría de los casos no son conocidos más allá de nuestras fronteras. El editor de El Artista, con aires de un marcado nacionalismo, especifica a este respecto que sólo se nombran los más destacados, puesto que únicamente se pretende entretener al lector y no crear una exhaustiva narración de historia ${ }^{7}$.

6. El Semanario Pintoresco Español es claro a este respecto, tal y como indica en su Prospecto fechado en 1836: «Los grandes hechos históricos de que el mundo ha sido testigo, las noticias biográficas de los hombres ilustres por su saber y patriotismo, sirven para inspirar el deseo de imitarles, y para reconciliarles aquel respeto público a que son tan acreedores; y bajo este aspecto la historia ocupará no pequeña parte de las páginas de nuestro Semanario».

7. Este editorial aparece sin firma, pero el índice del primer tomo es atribuido a Eugenio de Ochoa, coeditor de la revista.

Anales, 25, 2013, pp. 149-168 
Esta publicación vio la luz con el propósito de popularizar entre los españoles la afición a las Bellas Artes, según declaración del referido prospecto de la revista, objetivo que no contenía ningún manifiesto romántico sino más bien resaltaba el propósito docente de la obra (Calvo Serraller y González García 1978, pág. 1). En definitiva, se trata de una publicación que tiene sus orígenes en el despotismo ilustrado, y cuyo fin es el adoctrinamiento en artes:

El objetivo de este periódico- afirmaba- no es otro que el de hacer populares entre los españoles, los nombres de muchos grandes ingenios, gloria de nuestra patria, que sólo son conocidos por un corto número de personas y por los artistas extranjeros que con harta frecuencia se engalanan con sus despojos. Contendrá esta revista biografías de hombres célebres, discursos sobre las Bellas Artes, descripciones de monumentos antiguos y modernos, noticias de descubrimientos curiosos, tanto en nuestra nación como en las extranjeras, todo en fin lo que pueda deleitar e instruir a nuestros lectores (Randolph 1996, pág. 27).

Se trataba de un periódico, en suma, «dedicado a la glorificación de España por medio de sus grandes hombres, y a la edificación de su pueblo, reflejando así el ideal herderiano del Romanticismo nacional, con ciertos arrastres de la Ilustración» (Randolph 1996, pág. 27).

La defensa de la dignidad de las Bellas Artes es uno de los objetivos más destacables de la revista, pues exige la justa valoración social de todos aquellos que se dedican plenamente al arte. Pedro de Madrazo se muestra indignado en El Artista por la actitud de quienes consideran al arte como una clase de industria y valoran más otros oficios útiles porque desconocen el esfuerzo que conlleva su práctica. El arte es concebido como una forma de vida, similar a la religión. En este sentido, Ochoa mira con añoranza la valoración social de la práctica artística en otros tiempos, concretamente hacia el siglo XV, momento en el que el artista toma conciencia de su valía y se representa como un ser de cualidades excepcionales. Entonces no había término medio, el que era artista, sabio o poeta, lo era por entero y como expresaba Eugenio de Ochoa en el número 19 de la revista "consagraba sus facultades, su amor, su vida, todo su ser al ídolo sublime del arte» (pág. 226). La idea que El Artista deseaba transmitir a sus lectores es que el arte es una religión, que exige vocación y dedicación.

Cuando en 1834 Federico de Madrazo y su amigo Eugenio de Ochoa solicitan a la Reina Regente el permiso de publicación de una revista con el fin de popularizar entre los españoles la afición de las Bellas Artes, especifican su metodología de trabajo: « [...] para lo cual contendrán todos sus números retratos y biografías de hombres célebres, como también descripciones de monumentos y trozos de amena literatura». Coincide, como la mayoría de 
estas publicaciones de corta vida, con el Romanticismo tardío de la época de reinado de Isabel II $^{8}$.

En esta línea, los editores de la revista que llenó el vacío dejado por El Artista, la titulada El no me olvides, se defienden de la crítica anti-romántica mediante la pluma de Jacinto Salas Quiroga y apoyan la idea de un Romanticismo como germen de las virtudes sociales. A su vez, la perecedera revista inaugurada por El Liceo en 1837 y titulada El Liceo Artístico y Literario es considerada también como uno de los símbolos del movimiento romántico de la capital (Pérez Sánchez 2005, págs. 93-105). Tal como planteaba en sus primeros estatutos Fernández de la Vega, pretendía conseguir «el fomento y la prosperidad de las Bellas Artes» ${ }^{9}$. Patricio de la Escosura, abogaba en sus páginas por el Romanticismo en arte y poesía, movimiento literario que compara con el Siglo de Oro español en el que los creadores quedaban sometidos a la arbitrariedad moral de los poderosos. Así pues, este arte del pasado se hallaba lejos del arte moderno, el romántico, que tenía un claro carácter social. La nueva critica se referirá de modo más favorable al siglo XVIII, aunque en el arte o la poesía sea declarado inferior al Siglo de Oro.

El nexo común de todas estas publicaciones será un afán educativo que les lleva a rescatar la figura de artistas pasados. Así pues, en su actividad no actuaron como un círculo cerrado que promocionaba exclusivamente el arte contemporáneo sino más bien representaban publicaciones abiertas que, gracias a la promoción de artistas de siglos anteriores ya fallecidos, llegaron a facilitar que los coleccionistas de dichos artistas compartieran sus obras con el gran público a través de instituciones como el Liceo. De este modo, cuando en 1846 el Liceo organiza su gran exposición de Bellas Artes se intenta exponer las obras más relevantes no sólo de artistas vivos sino de los fallecidos. Es importante destacar, que el genio velazqueño, ya en estas fechas, se vio ensombrecido por la presencia goyesca, que eclipsó con sus lienzos al público liceístico. En esta exposición se mostraron obras de creadores no contemporáneos, y junto a los lienzos de Goya se colgaron otros de Zacarías González Velázquez, de José López Enguídanos o de Mariano Salvador Maella. Este deseo de difundir la cultura española con preeminencia sobre manifestaciones

8. Sobre la fortuna crítica de las revistas románticas españolas véase «Estudio preliminar» a la edición de El Artista elaborado por González García y Calvo Serraller (1981, págs. 9-29).

9. Véase el artículo primero de «Capítulo Primero: del Liceo en general y de los Socios», publicado en Constituciones del Liceo Artístico y Literario de Madrid: redactadas con arreglo a las modificaciones hechas por las Juntas General y Delegada hasta el 25 de noviembre de 1840 (1840, p.3).

Anales, 25, 2013, pp. 149-168 
artísticas foráneas, vendrá definido por el genio y carácter español o el genio del país. Mejor que ningún otro, el pintor que personificará este genio es D. Francisco de Goya y Lucientes que para muchos representaba los aspectos clave de la leyenda española tal como era imaginada por los literatos extranjeros. Para Calvo Serraller (en García Felguera 1991, pág. 12) la reivindicación de la pintura española vino de Europa gracias a los románticos franceses y británicos, mientras que los españoles actuaron a remolque. Los primeros defensores entusiastas de la obra de Goya fueron los franceses y, poco después, una corriente romántica de hispanofilia recorrió Europa descubriendo de modo universal las figuras Velázquez y de Goya con Richard Fox y William Stirling-Maxwell.

Siguiendo esa intención divulgativa que caracteriza a la mayoría de estas publicaciones, El Artista eligió como protagonista de su primer número la vida y obra de Velázquez (AA. VV. 2002). Con estas palabras justificará su director Eugenio de Ochoa la necesidad de escribir tal biografía: «nos ha parecido justo contribuir en lo posible a generalizar la fama de este gran hombre [...]». Para ello acude a fuentes literarias biográficas españolas — tales como las de Pacheco, Palomino o Ceán Bermúdez- ofreciendo un completo bosquejo de su vida. Esto sirvió de ejemplo a El Semanario Pintoresco Español, que reprodujo los anteriores textos íntegros pero añadió como acompañamiento nuevos grabados xilográficos. En El Siglo Pintoresco (1845) de Pedro de Madrazo, que ya había publicado el nuevo catálogo del Museo del Prado (1843), se describen alguno de los cuadros del célebre pintor que se exhiben en la sala de la escuela española.

Para poder entender ese afán de revitalización del arte hispano, en lo referido al siglo dieciocho, conviene destacar el nexo que enlaza la vitalidad de un nacionalismo popular en sus manifestaciones artísticas con la corriente de exaltación de la singularidad propia de estas publicaciones del Romanticismo. A través de Mesoneros Romanos se aprecia el nacimiento de un movimiento costumbrista romántico madrileño que se inserta en la corriente iniciada en el último cuarto del siglo XVIII con Goya. La penetración peninsular de los ideales nacionalistas europeos reinstituye en gran medida la necesidad de redescubrir la realidad española nacional, regional y local. En las artes podemos ver un idílico retorno en búsqueda de una identidad perdida. En este contexto, a través de las publicaciones periódicas, se produce una continuidad ideológica, temática y estética (Castro 2003, págs. 742-750). También podemos observar cómo algunas de estas revistas programáticamente románticas en los primeros años del siglo diecinueve se alzaron para criticar la labor de la Academia. Por esta razón, don José Negrete, conde Campo Alange, publicará en El Artista un artículo bajo el título de «A la Aristocracia Española» donde reflexiona sobre 
la situación social del arte proponiendo un nuevo sistema de libre mercado para el desarrollo de las artes y rechazando de este modo como inviable el sistema de protección y dispendio público del que hacían gala las academias ${ }^{10}$. Ochoa apoyaba en parte esta postura, y proponía que el Gobierno interviniera en el arte pero solo como canal para regenerar, ilustrar y estimular el buen gusto. En su preámbulo a «De los Artistas Españoles» diserta sobre la escasa importancia del artista en la España de entonces y explica cómo la intervención del Gobierno se hace necesaria porque el público, para el que se hacen las obras, no compra y es incapaz de apreciar su valor estético puesto que en definitiva es un público ignorante. Se reitera por tanto la necesidad de una buena pedagogía en lo relativo a las artes y al buen gusto.

A pesar de las líneas de continuidad establecidas entre las publicaciones periódicas con ciertos presupuestos ilustrados, y puesto que los aires de renovación que soplaban en los años treinta en la península se convirtieron en tempestades en los cincuenta, resulta necesario para nuestro discurso destacar la importancia de las innovaciones propiamente románticas. Nikolaus Pevsner, en su magnífico estudio sobre estas instituciones destaca la rebelión que a principios del siglo XIX llevaron a cabo los artistas contra las academias como órganos caducos y anacrónicos (Pevsner 1982). En Europa, este movimiento antiacadémico estaba desarrollándose desde finales del siglo XVIII con la llegada del Romanticismo, especialmente temprano en el caso alemán. En el seno de la Real Academia de San Fernando encontramos el célebre informe presentado a la institución en 1792 por Francisco de Goya, en el que reiteraba la necesidad de reformar la enseñanza de la pintura «desterrando toda sujeción servil [...] y otras pequeñeces que envilecen, y afeminan un Arte tan liberal y noble como es la Pintura» ${ }^{11}$. Encontramos el apogeo de esta misma tendencia en José Galofre y Coma, quien en su primer libro titulado El Artista en Italia (1851) arremete contra las academias y sus enseñanzas artísticas, promulgando la necesidad de reformar las mismas. La única posibilidad que les quedará a estas instituciones será su transformación en escuelas públicas donde masivamente se promocionará la formación de buenos artesanos. En sus páginas advierte que el gran error de esta institución ha sido pretender elevar a rango

10. Militar liberal y romántico, José Negrete fue uno de los principales animadores de El Artista. Muerto muy joven en la guerra carlista, Larra le dedicó una sentida elegía bajo el título «Necrología. Exequias del conde de Campo Alange», publicadas el 16 de enero de 1837 en El Español.

11. Este informe fue redactado entre 1786 y 1792, siendo entregado a la Academia con fecha de 14 de octubre de 1792. Se conserva en el Archivo Academia de San Fernando con signatura 1-18/1 y fue publicado en primera instancia por Jutta Held en 1966. 
universitario su formación, transformando así a excelentes artesanos en mediocres artistas. Este autor ataca especialmente a los representantes del arte oficial de nuestro país, es decir, el clan Madrazo. Durante el período de 1852 a 1858, tanto en la prensa como en el Parlamento, José Galofre, que durante su estancia en Roma estuvo muy cerca de los círculos nazarenos, desarrolló una auténtica campaña publicitaria para concienciar al público sobre la necesidad de reformar o eliminar las academias. En otro de los artículos del mismo autor se comenta acerca de las diversas escuelas nacionales - florentina, romana, veneciana, flamenca y española - y se advierte que ninguna de ellas es fruto de las academias, sino del genio y la inspiración de los artistas (Galofre 1853).

Un ligero repaso de las numerosas biografías y narraciones -más o menos noveladas- que las revistas de la primera mitad del siglo XIX incluyeron en sus páginas sobre la vida de célebres artistas del pasado, nos muestra que nuestros escritores no sólo comprendieron el concepto de genio desarrollado por el Romanticismo europeo, sino que realizaron también conscientemente una lectura parcial del mismo (Mari 1989). El concepto de genio quedó, por tanto, en un valor puramente melodramático lleno de afectividad, pero falto de contenido teórico, ya que no hacían referencia a la libertad del artista creador (Romero Rodríguez 1995, págs. 123-140).

Frente a esa ausencia resulta sorprendente que desempolvaran argumentos de viejas polémicas sobre la ingenuidad y nobleza de la pintura con el fin de demostrar la superioridad del genio sobre cualquier otra actividad ${ }^{12}$. Esta nobleza se demostraba además en los mismos términos que en el siglo XVII, es decir, citando con abusiva frecuencia los casos de favor o privilegio concedidos por reyes, príncipes o papas a la grandiosidad del artista. En este sentido, las anécdotas preferidas eran las de la Cruz santiaguista de Velázquez, o la contestación de Alonso Cano al Oidor de Granada, añadiéndose además historias sobre la dignificación de toda persona que desarrolla cualquier tipo de actividad artística.

Mercedes Replinger (1988, págs. 37-42) plantea que la insistencia en estos planteamientos un tanto anacrónicos podría estar tal vez justificada, por un lado, por el retraso con que se alcanzó en nuestro país la separación

12. Los textos, «Pintor-Pintura» firmado por De Ochoa (1835, págs. 256-257) y «Profesión, arte, oficio, profesor, artista, menestral» de Usoz del Río (1835, págs. 178-180), publicados en El Artista intentaban establecer nítidas distinciones terminológicas para definir al artesano como oficio frente al artista como creador, llegando a proponer para el Diccionario de la Lengua Española un nuevo vocablo: «pintador», aquel que «profesa o ejerce la pintura, considerada como oficio mecánico» y reservar el de pintor para «el que profesa o ejerce la pintura, considerada como arte noble». 
definitiva entre el artista y la academia, y por otro lado, como también han señalado Calvo Serraller y González García, debido a la preocupación de los románticos por el nuevo destino social del artista contemporáneo (1978b, págs. 40-59). Estas teorías resultan bastante probables si tenemos en cuenta la queja de Pedro Madrazo (1835, pág. 14) sobre la pervivencia en España de la consideración de la actividad artística como una profesión «vil y mecánica» y las palabras de Eugenio de Ochoa: «El primer paso que hay que dar en España para elevar el arte a la altura que le pertenece, única en que es posible su existencia, es destruir toda preocupación contraria a su dignidad, apreciarle como lo que él vale, es decir, como la cosa más sublime en que puede emplearse la inteligencia del hombre» (De Ochoa 1836, pág. 26).

\section{Estimación y recuperación del oficio de grabador}

En el siglo XIX los discursos de prestigio de una nación fueron parte de la afirmación de su pasado y su cultura, y en ello las Bellas Artes jugaban un papel esencial. En este ambiente, España no quedaría ajena a este movimiento, y dio muestras de una rica, combativa, y a veces erudita literatura reivindicativa a través de la cual se opuso y contestó a los desprecios de las naciones dominantes en Europa. Desde el siglo XVIII se pretendió cambiar la noción negativa que otros tenían de la península ibérica y gracias a las plumas de escritores y eruditos, como Ceán Bermúdez, Antonio Ponz o Eugenio Llaguno, quedó constancia escrita de nuestro avance y prestigio, equiparando nuestra producción a la del resto de Europa. En la renovada identidad de España que persiguió la ilustración nacional, las Bellas Artes ocuparon un destacable lugar.

En este contexto editorial podemos ver cómo el arte del grabado y su profesión experimentaron un considerable auge con la llegada de la prensa ilustrada. Gran parte de los retratos de artistas contenidos en las páginas de estas publicaciones periódicas trataban de resaltar la figura de estos artífices a través de la unión de su biografía y retrato, con imágenes que podían ser copiadas o de nueva factura. A través de este medio, sus efigies lograron gran difusión puesto que posteriormente se emplearían en las más diversas ediciones, incluso en los medios de masas ${ }^{13}$.

Parece claro que el punto de inflexión sobre la valoración social de los grabadores se produjo tras el cambio dinástico; durante la primera mitad del siglo XVIII estos artistas serán considerados como meros artesanos al servicio de la devoción religiosa o de las exigencias editoriales, entregándose a las

13. El retrato del grabador Valenciano Rafael Esteve fue posteriormente utilizada para la impresión de los billetes de 50 pesetas por el Banco de España, Madrid, 1874. 
necesidades de incorporar algunas ilustraciones a los textos que ellos mismos editaban (Silva Maroto 1989, págs. 401-411). Su oficio y formación fue de poca relevancia hasta bien entrado el citado siglo, gracias al establecimiento de la enseñanza oficial por parte de las academias. En la asamblea preparatoria, 1744-1752, y en los estatutos de 1751 ni siquiera se mencionan los profesores de este arte.

El 23 de junio de 1753 la Junta de la Academia acordó presentar al rey la evidente necesidad de promover el estudio de este arte, y para ello solicitaban la creación de seis plazas destinadas a jóvenes que no tenían posibilidades económicas. El Estado convocó tres plazas para el grabado a buril y tres para el grabado en hueco. De entre los opositores, las plazas de grabado a buril fueron obtenidas mediante concurso por artistas que quedaron bajo la dirección del maestro grabador Juan Bernabé Palomino (García Melero 2001).

Para encontrar la primera mención honorífica a los profesores de este arte en el seno de la Academia habrá que esperar a la Distribución de los Premios de 1754, donde se menciona que: «desde el establecimiento de la Academia se tuvo por preciso procurar los adelantamientos del arte del grabado, tanto en el uso del buril y agua fuerte como en la formación de sellos, cuños y demás especies; así, para la más fácil propagación de las producciones de las tres artes, como otros innumerables fines» (1754, pág. 15). Para ello designó desde el 12 de Abril de 1752, fecha de la creación oficial de la Academia, a Tomás Francisco Prieto como grabador de medallas y a Juan Bernabé Palomino como grabador en dulce y de cámara del rey. Un síntoma de la precaria situación de la actividad del grabador y de su escaso número, así como de la limitada importancia que se le concedía, es su carencia de organización gremial hasta bien entrado el siglo XVIII. El grabado calcográfico original, es decir, aquel que no reproduce imágenes y es una obra completa en sí misma, fue bastante pobre en España.

Los nuevos Estatutos de 1757 ya contemplan la enseñanza de grabado, de la cual se encargarán dos directores como venía sucediendo desde 1752. En este mismo año la Academia puede escribir con orgullo que los progresos realizados en el utilísimo arte del grabado son ya notorios, pero que, sin embargo, se cree «muy conveniente añadir nuevos estímulos proponiendo a sus profesores un premio extraordinario, para darlo al mismo tiempo que se reparten los ordinarios de las tres Nobles Arte» (1757, pág. 2).

El año de 1792 será decisivo para la enseñanza en la Academia con el nombramiento de Bernardo de Iriarte como viceprotector y la reorganización de los estudios. Manuel Salvador Carmona redactó un informe para la reforma de la enseñanza del grabado que dio a conocer en la Junta, donde especificaba 
que sus alumnos copiaban las estampas de Gerard Audran y Antoine Masson, grabadores que habían adquirido gran admiración por la delicadeza de su buril. Para Salvador Carmona lo fundamental era copiar las obras de los grandes grabadores hasta adquirir un gran nivel, aconsejando la lectura de la obra de Manuel de Rueda sobre la técnica del grabado. A pesar de estos avances, hasta finales del XIX la cátedra de grabado en nuestro país estará en manos de grabadores de reproducción, por lo que puede resultar comprensible la poca estima que se prestó entonces a este arte.

El vehemente deseo de los grabadores de verse considerados como artistas de las Bellas Artes no se vio realizado hasta 1820. Según reglamento previo, la costumbre para la nominación de este cargo «ha sido siempre de la libre voluntad de S.M.».

El primer grabador de la Real Cámara de los Borbones ${ }^{14}$, en 1719, fue Juan Bernabé Palomino, aunque no recibiría tal plaza hasta noviembre de 1736. En su caso, se trató de un puesto sin sueldo hasta 1738, año en el que se le concedieron 400 ducados anuales, resultando que lo que se suponía un título honorífico, concedido como premio y estímulo, se convirtió en diversas ocasiones en un castigo.

Carlos José Flipart fue el único que, según Ceán Bermúdez, ostentó los títulos de pintor y grabador de cámara en 1750. No obstante, parece que el titulo de grabador no fue efectivo, pues oficialmente se consideró vacante la plaza desde la muerte de Palomino en 1777 hasta el nombramiento de Manuel Salvador Carmona en 1783. A este respecto, Floridablanca ${ }^{15}$ indica que:

En premio de la habilidad de don Manuel Salvador Carmona, director del grabado dulce de la Real Academia de San Fernando, y teniendo consideración al crédito que con sus obras ha adquirido de ser uno de los primeros grabadores de Europa, le ha nombrado S. M. por su Grabador de Cámara, cuya plaza ha estado vacante desde que murió don Antonio (por Juan Bernabé Palomino) con 8.000 reales de sueldo, debiéndole cesar la pensión de 6.000 reales que se le conservó y ha gozado desde que volvió de París, donde estuvo pensionado (Carrete Parrondo, Checa Cremades y Bozal 1987, pág. 471).

14. Analizaremos este tema ciñéndonos al grabado calcográfico, ya que se trata de la técnica comúnmente utilizada por los grabadores del siglo XVIII.

15. Esta preocupación por la consideración social de nuestros artistas y el deseo de toma de conciencia social sobre la producción artística hispana, se remonta siglos atrás, no obstante será el propio Floridablanca quien autoriza a Antonio Canavilles o Juan Pablo Forner para resaltar las glorias de España. La propia academia tomaría cartas en el asunto en 1785 convocando un concurso de Oratoria defendiendo los progresos en artes y ciencias llevados a cabo por la nación. 
En 1801, cuando hay un total de seis grabadores de cámara, Carmona se creyó con derecho a ostentar la distinción de poder ser titular por ser el más antiguo, a semejanza de los pintores, es decir, primer grabador de cámara. Pero la pretensión tuvo resultado negativo. Pese a la negativa, en tres ocasiones firmó las láminas como primer grabador de cámara.

Fernando Selma, sin haberlo solicitado, fue nombrado en 1799 grabador de la real cámara. La actitud del artista durante el gobierno de José I fue de no colaboracionismo, por lo cual murió sin haber publicado sus principales obras.

Si hasta entonces el nombramiento de grabadores de cámara se había producido de una forma espaciada — cinco en sesenta y cinco años-, a partir de 1801 se incrementa el número con el nombramiento de tres nuevos. En 1808 este aumentó considerablemente para incluir, entre otros, a José Assensio y Torres, Juan Moreno Tejada, Rafael Esteve y Vilella, Tomás López Enguídanos y Perles o Vicente Mariani y Todoli. Por otra parte, Blas Ametller, que había sido discípulo de Manuel Salvador Carmona, también solicitó ser nombrado grabador de cámara en 1814 y fue nombrado como tal en 1815.

No obstante el proyecto redactado en 1816 por Felipe Cardano Bauzá para la creación de una escuela de grabado, puesto que la Real Academia de San Fernando no contaba con profesores, no se llevaría a cabo. Paralelamente, una nueva técnica, la litografía, se introducía en España acaparando la protección y promoción real. A pesar de estos primeros avances en la revalorización de esta labor, la fama alcanzada por los grabadores patrios no será comparable a la alcanzada por otros coetáneos europeos.

El arte del grabado será revisado gracias al espíritu de la Ilustración y a sus círculos de eruditos. Estos reflexionarán sobre la historia del grabado en España y la importancia del artista grabador. Hasta entonces no se había promulgado legislación alguna sobre esta profesión. Solamente, Antonio Palomino equipara en su Museo Pictórico (1715) el grabado a la pintura, considerándolo como arte liberal. Los testimonios que tenemos sobre su estatus y valoración social se los debemos a la literatura artística de la época. Anteriormente, el propio García Hidalgo había tenido palabras dedicadas a este arte en su tratado. En esta época es cuando se construyen los primeros repertorios de artistas, donde los grabadores tendrán un puesto importante, y cuando aparecen los primeros ensayos de literatura técnica en torno al grabado

El origen de la historiografía española sobre el grabado está sin duda en el «Discurso histórico sobre el principio y progresos del grabado», de José de Vargas Ponce, leído en la Junta pública que celebró la Real Academia de San Fernando el 4 de agosto de 1790 y publicado en la Distribución de Premios de 
aquel mismo año. Aporta noticias sobre la historia del grabado de su tiempo, y hace un primer balance de la situación del grabado ilustrado añadiendo interesantes reflexiones sobre las causas de su escaso cultivo en España.

En lo relativo a los repertorios de artistas, Ceán Bermúdez es la principal fuente de esta época a través de su Diccionario (1800), y él mismo fue consciente de su aportación. Menos conocido es el manuscrito anónimo titulado Noticias, documentos y papeles para formar un diccionario de pintores, escultores y grabadores. Obra trabajada en esta Corte, por un apasionado de las Bellas Artes (1796) digno de consulta aunque aporte pocas novedades. Conservado en la Biblioteca de la Fundación Lázaro Galdiano, reúne un conjunto de 388 papeletas con fichas de artistas ordenadas alfabéticamente en las que se recogen informaciones desiguales sobre fechas y obras, y en la que se encuentran incluidos los grabadores. La Biografía Pictórica Valentina de Marcos Antonio de Orellana, presenta algunas noticias interesantes aunque circunscritas al ámbito geográfico levantino.

Manuel de Rueda, comisario extraordinario del Estado Mayor para la Real Artillería, estampó Instrucción para grabar en cobre y perfeccionarse en el grabado a buril, al aguafuerte y al humo, con un nuevo método de grabar las planchas para estampar en colores a imitación de la pintura, y con un compendio histórico de los más célebres grabadores que se han conocido desde su invención hasta el presente (1761). Esta obra es en realidad poco original, porque traduce tratados perfectamente conocidos, desde el trabajo del propio Bosse, el primero sobre técnicas calcográficas, a otros más modernos. A pesar de ello, este manual fue muy usado y no superado ni tan siquiera en el siglo XIX. Algunos grabadores lo completaron con técnicas nuevas, como la aguatinta o el grabado a la aguada, pero sin abordar un tratado general sobre la materia.

Juan Moreno de Tejada también fue continuador del espíritu didáctico de la Ilustración. Fue autor de un poema en cuatro silvas titulado Excelencias del pincel y del buril, publicado en 1804. Dedicó la última silva al grabado, que llamó "pintura monocromática». Conceptualmente es probable que se inspirara en Las Investigaciones fiolosóficas sobre la belleza Ideal escritas por Esteban de Arteaga, quien a su vez se inspiró en Mengs. Moreno estudió el arte del grabado y se declaró autodidacta porque consideraba a Palomino demasiado antiguo y porque Carmona estaba fuera en París, hecho que nos hace intuir la necesidad latente de revisar las enseñanzas académicas.

Analizando la literatura artística coetánea y estudiando el progreso pedagógico establecido en el seno de la Real Academia de San Fernando, constatamos el creciente interés que la profesión del grabado tuvo a partir del siglo XVIII en la península. Dicha labor comenzó a ser valorada y defendida en una 
doble vertiente: artística y didáctica. Estos cambios tienen su fiel reflejo en la prensa ilustrada que revisamos en el presente estudio, a través de cuyas páginas se manifiesta la necesidad de recuperar las Bellas Artes como vehículo para el avance de la sociedad, promoviendo la libertad creadora e incrementando la estima hacia los artistas primigenios.

\section{Bibliografía}

AA.VV., Velázquez en la prensa española del siglo XIX, Hemeroteca Municipal de Madrid: Testimonios de prensa, no. 2, 2002.

AlboRG, Juan Luis, Historia de la literatura española: El Romanticismo, Vol. 4, Madrid, Gredos, 1980.

AlONSO CORTES, Narciso, Zorrilla, su vida y sus obras, Valladolid, Imprenta Castellana, 1943.

BEDAT, Claude, La Real Academia de Bellas Artes de San Fernando (1744-1808), Madrid, Fundación Universitaria Española, 1989.

BOIX, Félix, Obras ilustradas sobre arte y arqueología de autores españoles publicadas en el siglo XIX.: Discurso leído ante las seis Reales academias, reunidas en la de la Historia para conmemorar la «Fiesta del libro,» el día 23 de abril de 1931, Madrid, Gráficas Marinas, 1931.

Calvo Serraller, Francisco y González García, Ángel Lorenzo, «Estudio preliminar», El Artista: Madrid, 1835-1836, Madrid, Turner, 1981, págs. 9-29.

Calvo Serraller, Francisco y González García, Ángel Lorenzo, «El Artista» y la difusión de la vanguardia artística en España», en El arte del siglo XIX: II Congreso Español de Historia del Arte. (Valladolid, 11-14 de diciembre de 1978), Vol. 1, Madrid, 2007a, págs. 1-2.

Calvo Serraller, Francisco y González García, Ángel Lorenzo, «Polémicas en torno a la necesidad de reformar o destruir la Academia durante el Romanticismo español», en El arte del siglo XIX: II Congreso Español de Historia del Arte. (Valladolid, 11-14 de diciembre de 1978), Vol. 1, Madrid, 2007b, págs. 40-59.

Carrete Parrondo, Juan, Checa Cremades, Fernando y Bozal, Valeriano, El grabado en España; siglos XV al XVIII, SUMMA ARTIS, Vol. XXXI, Madrid, Espasa Calpe, 1987.

CARRETE PARRONDO, Juan, et al., El grabado en España; siglos XIX y XX, SUMMA ARTIS, Vol. XXXI, Madrid, Espasa Calpe, 1988.

CARRETE PARRONDO, Juan, El grabado calcográfico en la España Ilustrada, Madrid, Club Urbis, 1978.

CAstro, María A., «Goya fuente de inspiración en la narrativa de Mesonero Romanos». Hispania, Vol. 64, no. 4, (2003), págs. 742-750.

CRUZADA VillaAmil, Gregorio, «Dos aguafuertes inéditos de Leonardo Alenza». El arte en España, III, 1865, págs. 304-306. 
FERRI COLL, José María, «El Artista y la ideación romántica de los géneros españoles». Arbor, Vol. 188, no. 575, (2012), págs. 959-964.

GALOFRE, José. 17 de febrero 1853, «Nobles artes», La Nación.

García Felguera, María de los Santos, Viajeros, eruditos y artistas: los europeos ante la pintura española del siglo de oro, Madrid, Alianza Editorial, 1991.

GARCía MELERO, José Enrique, Arte español de la Ilustración y del siglo XIX: en torno a la imagen del pasado, Madrid, Encuentro, 1998.

GARCía MELERO, José Enrique, Literatura española sobre artes plásticas: bibliografía impresa en España entre los siglo XVI y XVIII, Madrid, Ediciones Encuentro, 2001.

Gallego, Antonio, Historia del grabado en España, Madrid, Cátedra, 1979.

GÓMEZ BACEIREDO, Pilar, «Textos biográficos en el semanario ilustrado español El Artista (1835-1836): tipología y características generales». Anagramas: Universidad de Medellín, Vol, 9, no. 17, (2010), págs. 15-30.

De OchoA, Eugenio [1835], El artista: Madrid, 1835-1836, ed. Francisco Calvo SERraller y Ángel Lorenzo GonZÁlez Garcia, Madrid, Turner, 1981.

HelD, Jutta, «Goya's Akademiekritik». Munchner Jahrbuch der Bildenden Kunst, Vol. 17, (1966), págs. 214-224.

HenARES CUEllar, Ignacio y Calatrava Escolar, Juan, Romanticismo y teoría del arte en España, Madrid, Cátedra, 1982.

HERNANDO, Javier, El pensamiento romántico y el arte en España, Madrid, Cátedra, 1995.

LÓPEZ SANZ, Genoveva Elvira, «Romanticismo frente a clasicismo en El Artista (1835-1836)». Espéculo. Revista de estudios literarios, Universidad Complutense de Madrid, no. 14, (2000).

MARI, Antonio, Euforión: espíritu y naturaleza del genio, Madrid, Tecnos, 1989.

Mesonero Romanos, Ramón, Memorias de un setentón, natural y vecino de Madrid, Vol. 2, Madrid, Oficinas de la Ilustración Española y Americana, 1881.

PEERS, Edgar Allison, «Romanticismo y eclecticismo», en Romanticismo y Realismo: Historia y crítica de la literatura española, coord. Iris M. ZAVALA, Vol. 5, t.1, Barcelona, Crítica, 1982, págs. 48-53.

PÉREZ SÁnCHEZ, Aranzazu, «La presencia de Goya y lo Goyesco en el Liceo Artístico y Literario de Madrid». Goya, no. 305, (2005), págs. 93-105.

Pevsner, Nikolaus, Las Academias de Arte, Madrid, Cátedra, 1982.

RANDOLPH, Ronald Allen, Eugenio de Ochoa y el Romanticismo Español, Berkeley y Los Angeles, University of California Press, 1966.

Real Academia de Nobles Artes de San Fernando, Distribución de los premios concedidos por el Rey N.S. a los discípulos de las tres Nobles Artes, hecha por la Real Academia de S. Fernando en la Junta General de 6 de Febrero de 1757, Madrid, Gabriel Ramírez, 1757. 
Real Academia de Nobles Artes de San Fernando, Distribución de los premios concedidos por el Rey N.S. a los discipulos de las tres Nobles Artes, hecha por la Real Academia de S. Fernando en la Junta General de 22 de diciembre 1754, Madrid, Gabriel Ramírez, 1754.

REPLINGER GONZÁLEZ, Mercedes, «El genio y la academia en la España romántica». Arte, individuo y sociedad, no.1, (1988), págs. 37-42.

RODRÍGUEZ GUTIÉRREZ, Borja, «La voluntad iconográfica y aristocrática de El Artista». Revista de Literatura, Vol. 73, no. 146, (2012), págs. 449-488.

ROMERO RODRíGUEZ, Julio, «Nullum mangnum ingenium sine mixtura dementiae: El miro del genio y la locura». Arte, individuo y sociedad, no. 7, (1995), pp. 123-140.

Romero Tovar, Leonardo, Panorama crítico del Romanticismo español, Madrid, Castalia, 1994.

SiLva MARoto, Pilar, «La influencia del grabado en el Arte de la época de Carlos III», en El Arte en Tiempos de Carlos III. IV Jornadas de Arte, (Madrid, 29 Noviembre - 2 de Diciembre de 1988), Madrid, Departamento de Historia del Arte «Diego Velázquez», C.S.I.C., 1989, págs. 401-411.

SimÓn DíAZ, José, El Artista, Madrid (1835-1836), Madrid, Instituto «Nicolás Antonio» del Consejo Superior de Investigaciones Científicas, C.S.I.C, 1946.

TAJAHUERCE, Isabel, «El artista y la pintura: la dificultad de una arte noble», Historia y comunicación social, no. 2, (1997), págs. 229-236.

VEGA GONZÁLEZ, Jesusa, «Modernidad y tradición en la estampa del siglo XIX». Anuario del Departamento de Historia y Teoría del Arte, no. 9-10, (1997-1998), págs. 367-378.

Fecha de recepción: 04/03/2013

Fecha de aceptación: 29/05/2013 